\title{
Psychosocial impact of early onset dementia among caregivers
}

\author{
Impacto psicossocial da demência de início precoce em cuidadores
}

Nathália R. S. Kimura, Virgínia L. R. Maffioletti, Raquel L. Santos, Maria Alice Tourinho Baptista, Marcia C. N. Dourado*

\begin{abstract}
Introduction: There is growing recognition of early onset dementia (EOD) as a significant clinical and social problem because of its effects on physical and mental health of people with dementia (PWD) and their caregivers.

Objective: To analyze the psychosocial impact of EOD in family caregivers.

Methods: The study design was qualitative. Nine EOD caregivers (7 women) were recruited at a service for Alzheimer's disease and assessed using semi-structured interviews. Interpretative phenomenological analysis was used to analyze caregivers' reports. Results: Five themes emerged from the narratives: psychological and emotional impact; physical impact; financial and professional impact; social impact and need for support services. The majority of the caregivers of people with EOD perceived their emotional wellbeing as poor or extremely poor. Carers reported poor physical health, which tends to be longer-lasting than mental health problems. Two caregivers had to retire after the disclosure of the dementia diagnosis, and seven reduced their work loads because they had to look after PWD. Preserving the abilities of PWD is essential to maintain their self-esteem, dignity and sense of utility. For the caregivers, interventions and stimulating activities make PWD feel worthwhile and contribute to improving life.

Conclusion: The caregivers of people with EOD assume the role of caregiver prematurely and need to balance this activity with other responsibilities. There is a need for more studies of EOD in order to improve understanding of the impact of this disease and to enable development of adequate services for PWD and their caregivers.
\end{abstract}

Keywords: Early onset dementia, caregiver, psychosocial impact, qualitative studies.

\section{Resumo}

Introdução: A demência de início precoce (early onset dementia, EOD) vem sendo reconhecida como um importante problema clínico e social devido aos efeitos sobre a saúde física e mental das pessoas com demência e seus cuidadores.

Objetivo: Analisar o impacto psicossocial da EOD em cuidadores familiares.

Métodos: 0 estudo baseia-se na metodologia qualitativa. Foram realizadas entrevistas semiestruturadas com nove cuidadores EOD (sete mulheres) recrutados em um serviço para doença de Alzheimer. Utilizou-se análise fenomenológica interpretativa para analisar as narrativas dos cuidadores.

Resultados: Cinco temas emergiram das narrativas: impacto psicológico e emocional; impacto físico; impacto financeiro e profissional; impacto social e necessidade de serviços de apoio. A maioria dos cuidadores percebe seu bem-estar emocional como ruim ou extremamente ruim. Os cuidadores reconhecem prejuízos na saúde física, que tendem a ser mais duradouros do que os problemas de saúde mental. Dois cuidadores tiveram que se aposentar após o diagnóstico de demência, e sete diminuíram sua carga de trabalho porque tinham que cuidar dos pacientes. Preservar as habilidades das pessoas com demência é essencial para manter a sua autoestima, dignidade e sentimento de utilidade. Para os cuidadores, intervenções e atividades de estimulação fazem com que as pessoas com demência se sintam mais úteis e contribuam para uma vida melhor.

Conclusão: Os cuidadores de pessoas com EOD assumem prematuramente o papel de cuidador e precisam equilibrar esta atividade com outras responsabilidades. Há necessidade de mais estudos sobre EOD, a fim de se obter uma melhor compreensão do impacto da doença e para o desenvolvimento de serviços adequados para pacientes e seus cuidadores.

Descritores: Demência de início precoce; cuidador; impacto psicossocial; estudos qualitativos.

\footnotetext{
* Center for Alzheimer's Disease and Related Disorders, Institute of Psychiatry, Universidade Federal do Rio de Janeiro (UFRJ), Rio de Janeiro, RJ, Brazil. Financial support: Fundação de Amparo à Pesquisa do Estado do Rio de Janeiro (FAPERJ; grant no. E-26/102.256/2010).

Submitted Jul 16 2015, accepted for publication Sep 06 2015. No conflicts of interest declared concerning the publication of this article.

Suggested citation: Kimura NR, Maffioletti VL, Santos RL, Baptista MA, Dourado MC. Psychosocial impact of the diagnosis of early onset dementia among caregivers. Trends Psychiatry Psychother. 2015;37(4):213-219. http://dx.doi.org/10.1590/2237-6089-2015-0038
} 


\section{Introduction}

Early onset dementia (EOD) is defined as a condition that has its onset among people under 65 years old. ${ }^{1}$ The prevalence of EOD is not as high as that of late onset dementia (LOD) ( $5 \%$ of all dementia cases), but it is increasingly recognized as a significant clinical and social problem. ${ }^{2}$ Alzheimer's disease (AD) has been described as the most common dementia diagnosis, even among young adults. Prevalence rates of $A D$ range from 1 to $66.7 \% .^{3}$ For clinicians, EOD poses several challenges that can include difficulties in establishing accurate diagnoses, because of the potential for confusion with psychiatric disease and the variability of onset within and between clinical syndromes, which can range from early adulthood up to the age of 65.4

When compared with LOD patients, people with EOD may present more frequent parietal disturbances, more neuropathological changes and more frequent family history, greater fronto-parietal/right hemisphere involvement, more frequent impairment of attention skills, better verbal fluency and motor-executive functions, and less delusion, hallucination, agitation, disinhibition and aberrant motor behavior. ${ }^{3}$ EOD is always accompanied by psychological and emotional difficulties, both for the person who has dementia and for their families. Furthermore, there are specific psychosocial issues and challenges that may add to the negative impact of dementia. Younger people with dementia (PWD) are more physically active and they suffer from lower self-esteem and feelings of worth, as well as extreme social isolation and marginalization, loss of independence (due to their difficulties with performing activities of daily living), financial insecurity, boredom and lack of significant occupation. ${ }^{5}$

All members of the family are affected directly or indirectly by EOD. Spouses and adult children are usually the main providers of informal care. ${ }^{6}$ In addition to cognitive and functional impairments, the presence of PWD significantly changes routines. Moreover, the amount of care needed increases over time, and caregivers may have to gradually neglect their own needs more and more. ${ }^{6}$

In comparison to the caregivers of people with LOD, the main caregiver of a person with EOD is more likely to have a longer duration of caregiving, has less social support, takes on a higher degree of burden and suffers from more symptoms of depression. ${ }^{2}$ Arai et al. ${ }^{7}$ have suggested that the caregivers of people with EOD have greater difficulties in coping with the behavioral disturbances than the caregivers of people with LOD. Studies comparing the age differences between caregivers suggest that older people's life experience allows them to develop a capacity to react positively to problematic situations and stressors. ${ }^{8}$ Younger caregivers are less likely to be sufficiently prepared for the role, perhaps due to reduced understanding and acceptance of the disease. ${ }^{7}$ An additional difficulty in EOD is the lack of social support: family members and friends, lacking knowledge about how to proceed, often reduce visiting the PWD or stop altogether, and do not offer support to the main caregivers. ${ }^{2}$

Numerous studies have demonstrated that caring for a person with EOD at home can have adverse effects on the psychological and physical health of the informal caregiver. $^{2}$ In Brazil, although the number of adults with EOD has been increasing, there is little information about the impact of this entity and the difficulties endured by their caregivers.

Therefore, this study aims to analyze the impact of EOD on family caregivers in Brazil.

\section{Methods \\ Design}

The study design is qualitative, based on analysis of caregivers' reports. We conducted face-to-face semistructured interviews which consisted of 10 questions about the following issues: obtaining a diagnosis; family and friends' reactions; changes to the routine; family organization; finances; leisure; the future; difficulties of the disease; treatment; health services; and caregiver's current situation. The questions were chosen to provide the information necessary to examine the impact of the condition on EOD family caregivers.

Interviews were recorded, transcribed and subjected to interpretative phenomenological analysis (IPA) ${ }^{9}$ to identify the key elements in the participants' perceptions and experiences. We applied IPA in this study because this methodology is particularly relevant to understanding subjective responses to diseases. The IPA method is considered phenomenological because it investigates the participants' views on a subject. It is also interpretative, since it recognizes the dynamic and interactive context from which the participants' perceptions are extracted, and the relationships between that context and the researcher's beliefs and perceptions. The investigator is involved in interpretative activity, attempting to give meaning to the participants' subjective world.

\section{Participants}

We recruited a convenience sample of caregivers ( $\mathrm{n}=9 ; 7$ women) (Table 1 ) who care for people whose 
age at onset was less than 65 years and who have been diagnosed with possible/probable $A D$, according to the criteria set out in the Diagnostic and Statistical Manual of Mental Disorders, 4th edition, text revision (DSM-IV-TR). ${ }^{1}$ All PWD were receiving clinical treatment at the Center for Alzheimer's Disease run by the Institute of Psychiatry at the Universidade Federal do Rio de Janeiro (CDA/IPUB/UFRJ), Brazil.

The clinical diagnoses were made on the basis of medical history interviews and laboratory and imaging exams. Cognitive screening tests and instruments for assessment of dementia severity (Clinical Dementia Rating $)^{10}$ and of presence of neuropsychiatric symptoms were also administered. All PWD were given cholinesterase inhibitors.

The primary family caregiver was defined as the person who was responsible for most care tasks. Each caregiver was able to offer detailed information about the PWD's life history, cognitive functioning and capacity to perform activities of daily living. All caregivers were previously informed about the diagnosis by the responsible psychiatrist. The sociodemographic characteristics of the PWD and their caregivers are listed in Table 1.

\section{Data analysis}

Qualitative analysis was conducted in order to arrive at a rigorous and comprehensive description of the issues. Some quotations were highlighted to illustrate the topics and, where possible, the participants' own words were used to label them. We began by reading and reviewing each transcript several times to become familiar with their contents. We took notes and compiled summary lists of key points, reproducing the participants' words as much as possible. These comprised the basis for identifying topics which emerged in each transcript, as key points were grouped together. At this stage, two investigators grouped key points independently and then compared the resulting data. Similarities and differences were examined, and differences were discussed until a consensus was reached. Closely related topics were grouped together under appropriate headings and clustered into sets. The result was a complete, hierarchically organized, summarized list of topics. Once the investigators had reached a consensus about the final set of topics, all of the transcripts were analyzed according to the topics, and a full list of extracts related to each topic was compiled (some of which are shown in translation in the results section). Finally, we engaged in an interpretative process to understand how these extracts integrate with or challenge current theory.

\section{Ethical issues}

This study was approved by the Ethics Committee at the Universidade Federal do Rio de Janeiro (UFRJ) Institute of Psychiatry. All caregivers signed an informed consent form before they were interviewed.

\section{Results}

Five themes emerged from the analysis of caregivers' narratives: 1) psychological and emotional impact; 2) physical impact; 3) financial and professional impact; 4) social impact; 5) need for support services.

\section{Psychological and emotional impact}

The psychological and emotional impacts are related to feelings and emotions inherent to the caregiving situation. Feelings of stress, grief or guilt, poor emotional wellbeing, impotence, frustration, sadness, depression, loneliness, feeling "robbed of the future" and anger are common among the caregivers

Table 1 - Sociodemographic characteristics of people with dementia (PWD) and their caregivers

\begin{tabular}{|c|c|c|c|c|c|c|c|c|c|}
\hline Caregiver & Gender & Age & Years in education & Employed & Kinship & $\begin{array}{c}\text { PWD } \\
\text { age }\end{array}$ & $\begin{array}{c}\text { PWD duration } \\
\text { of disease }\end{array}$ & PWD CDR & $\begin{array}{c}\text { PWD } \\
\text { employed }\end{array}$ \\
\hline 1 & $\mathrm{~F}$ & 57 & 8 years & Yes & Sister & 58 & 3 years & 3 - Severe & Yes \\
\hline 2 & $\mathrm{~F}$ & 31 & 15 years & Yes & Daughter & 55 & 9 years & 3 - Severe & Yes \\
\hline 3 & M & 59 & 11 years & No & Husband & 58 & 8 years & 3 - Severe & Yes \\
\hline 4 & $\mathrm{~F}$ & 59 & $>15$ years & Yes & Wife & 60 & 8 years & 2 - Moderate & Yes \\
\hline 5 & $\mathrm{~F}$ & 63 & 15 years & Yes & Wife & 67 & 5 years & 1 - Mild & Yes \\
\hline 6 & M & 66 & 4 to 8 years & No & Husband & 64 & 6 years & 1 - Mild & No \\
\hline 7 & $\mathrm{~F}$ & 58 & 11 years & Yes & Partner & 65 & 7 years & 1 - Mild & Yes \\
\hline 8 & $\mathrm{~F}$ & 34 & 15 years & Yes & Daughter & 69 & 5 years & 1 - Mild & No \\
\hline 9 & $\mathrm{~F}$ & 34 & 8 years & Yes & Daughter & 62 & 3 years & 1 - Mild & Yes \\
\hline
\end{tabular}

$\mathrm{CDR}=$ Clinical Dementia Rating; $\mathrm{F}=$ female; $\mathrm{M}=$ male; $\mathrm{PWD}=$ person with dementia. 
of people with EOD. ${ }^{2,11}$ In the caregivers' narratives we observed that they see life as disturbed by the onset of dementia at a stage at which it is thought to be improbable, since dementia is associated with elderly people.

In the beginning, I was desperate. I think that... as people say, "My world has fallen down." It really has fallen! It was difficult because we... both had a history of having the strength to survive and overcome problems... especially because he was very poor but he built a career and we had just bought a beautiful house. That house was the result of 20 years of hard work and, when we finally thought that now it was time to have fun, we started having one problem after another, until we had to come back to Rio de Janeiro. (Caregiver 4)

The role of caregiver for a person who develops a neurodegenerative disorder is complex, because the person receiving care is not the only one who suffers. The family caregiver can be understood to be a second patient. ${ }^{12}$ The caregiver may have to adapt to an unequal relationship in which he or she has to accept the role of being the caregiver to someone who gradually loses his or her functionality. Emotional problems resulting from a changing marital relationship and the loss of intimacy were often mentioned. ${ }^{2}$

Everything has changed. With the disease, we have started changing everything, including the fact that he was my source of strength and now we have changed roles. So, it is more difficult. (Caregiver 5)

The majority of the caregivers of people with EOD perceive their emotional wellbeing as poor or extremely poor. ${ }^{13}$ Caregivers' suffering can easily lead to a poor state of mental health, decreased physical health and lower quality of life. ${ }^{14}$ Sometimes, among LOD carers, becoming a caregiver can even be seen in a positive light, because of stronger beliefs related to the importance of caring. ${ }^{15}$ Conversely, because of their age, the caregivers of people with EOD may face greater difficulty in taking on the new role. The caregivers of people with EOD tend to make less use of coping strategies than do the caregivers of older adults ${ }^{8}$ and so they may experience an anticipated mourning, which is related to the changes brought on by dementia.

When I compare the way she was before and the way she is nowadays, I feel so sad. It is very hard, you know? Thank God, He has given me strength... well, if it was someone else, the person wouldn't handle the situation... but I don't like to see her this way. (Caregiver 6)

\section{Physical impact}

Caregiving activities are often related to the basic and instrumental activities of daily living and to providing psychological and emotional support. ${ }^{16}$ In common with family members caring for elderly people with $A D$, the caregivers of people with EOD described it as a difficult task that involved a physical burden. Caregivers tend to stop taking care of themselves.

I have a lot of problems to solve and I cannot solve them. Health problems. I need to have some operations. I have a lymphoma, can you see it? The operations have already been scheduled twice and I cannot see the doctor because of her. Because I don't have anyone to stay with her, and I don't trust anyone to take on the caregiving tasks. (Caregiver 3)

The carers report poor physical health, which tends to be longer-lasting than mental health problems. Informal caregiving may be linked with development of diseases or it may increase the risks of developing physical or mental disorders.

I feel bad when he is aggressive. I already have insomnia. I have an autoimmune disease, which gets worse when I feel depressed... I have never suffered from depression before, and neither has he. But, nowadays, I feel stressed, tense, and it makes my disease worse. And I feel afraid because my disease is very serious, I may have to be have a liver transplant. So, everything came at the same time, and it is very difficult. (Caregiver 4)

The physical impact may be because of the large numbers of hours dedicated to the caregiving tasks, the PWD's need for continuous attention, the lack of help and the multiple functions, such as caregiving, housework and taking care of other people in the household. ${ }^{16} \mathrm{High}$ levels of stress among caregivers of people with EOD may be related to the duration of the disease and to the lack of additional formal and informal care. ${ }^{7}$

\section{Financial and professional impact}

Certain types of age-related difficulties experienced by EOD caregivers appear to be specific to this group. Work-related problems and financial problems are less 
common in the case of LOD caregivers. ${ }^{2}$ It has been observed that there is financial tension caused by the loss of the PWD's employment. In some cases, the caregiver also loses their own job and there are also the expenses of care.

Financially, it has become even more difficult because we both worked. Then, he stopped working and I had to deal with our business all by myself. I cannot do anything else. And I just keep the clients that we had before he got sick. I cannot start anything bigger, because I don't have any help, because of him, you know. Because I have to look after him (...) I had to start living with my mom as well, because we don't have our own house and paying rent isn't that easy. So, I started living with my mom. (Caregiver 5)

Seven of the PWD in our sample were still working when the diagnosis of EOD was made. Moreover, two of the caregivers had to retire after the disclosure of the dementia diagnoses, and seven caregivers reduced their work loads because they had to look after the PWD. Younger caregivers have to deal with significant financial challenges. Diagnosis before the age of 65 years can lead to the loss of the primary income, can make it impossible to retire or force retirement or unemployment. These financial challenges may be applied to both (or either) the caregiver and the person with dementia.

When I started being a caregiver, I was looking after her full time ... That is why I found that it was so difficult to work as a lawyer in Rio de Janeiro, you know... Then I got a job, and I still work at the same place nowadays... because... errr... I mean, I didn't search for a great job because I had to stay with her and so on, until I hired a formal caregiver to help me and I could slow down. But, even with the formal caregiver, I had a lot of problems to solve. (Caregiver 2)

\section{Social impact}

The social impact is related to the social isolation, restriction of activities and low social support experienced by caregivers. The caregivers' routines are restricted to looking after the PWD, as if they had, definitively, had their lives bound to the PWD.

Terrible. My life is terrible. I don't have a life anymore... everyone says so. It isn't me. Everyone, my friends... nobody knows how I can handle it .... doing what I am doing... do you understand me? Because it is like I've told you, I don't have my own life anymore. I have her life combined with mine. I live her life. I don't go out. I cannot go anywhere. (Caregiver 3)

Because of the PWD's routine dependence on their caregivers, the caregivers start losing their own independence. They may feel that their plans for life are paralyzed. The social experience, i.e. the perceptions of the individual in the interpersonal relationships, helps in the capacity of continuing to offer physical and emotional support to the demands of the PWD. ${ }^{11}$

The caregiver and the family members may not agree with relation to the behaviors, attitudes and decisions that some of them adopt. ${ }^{16}$ In our study, we observed that some conflicts in the family context may be motivated by the division of responsibilities.

What is the strongest, in my opinion, is my relationship with my brother, which became worse... I don't think that it was completely bad, but nowadays we have been almost killing each other because of my mother's problem. (Caregiver 2)

\section{Need for support services}

It is common for family caregivers to have a series of needs, such as material needs (for financial resources, technical help, use of services), emotional needs (emotional support, support groups), and a need for information (how to take care of the patient, the symptomology of the disease and its progress, environmental and architectural adaptations, duties and rights). The need for specialized services for people with EOD and their caregivers has increased among this population.

The money I spend on medicine could be spent on other stuff. I think that we should be given the medication, but we don't get it. (Caregiver 1)

When I started treating Alzheimer's, I noticed that cognition has got worse. (...) This is clear from the tests. I mean, she has gone down from... I don't know... 23, on the Mini Mental score, to 13, 11, 15... So... it has been extreme and I think that...errr... the pharmacological treatment hasn't helped with anything. (Caregiver 2)

Institutional support services represent one of the coping resources when caregivers face difficulties in looking after someone with a chronic disease. In addition 
to the need for medical, psychosocial and financial support, there is a need for services that address the needs of PWD. According to the caregivers, stimulating interventions and activities make people with EOD feel more worthwhile and improve their lives. In relation to the nature of the disease, preserving the PWD's abilities is essential to maintaining their self-esteem, dignity and sense of utility. People with EOD tend to have very good physical health, which raises the possibility of using their residual abilities in activities adapted to their age. ${ }^{17}$

I think that he doesn't have any activities (...) Because he has always been someone attached to the value of money and to helping at home. So, he feels useless, he thinks that he is exploiting me. I tell him that he isn't. I say that it is his money that is used to maintain the house, not just my money. I explain everything to him. But I think that he needs activities. (Caregiver 4)

\section{Discussion}

We explored the psychosocial impact of EOD on caregivers. The five overarching topics that emerged from the participants' accounts reflected a tension between acknowledging life's responsibilities and the stress of caring for PWD. The caregivers of people with EOD prematurely assume the role of being a caregiver and need to balance this activity with other responsibilities, such as working and taking care of children. ${ }^{7}$ In many cases they feel obliged to prioritize caregiving instead of involving themselves in their plans for the future, such as job opportunities or personal development.

Although there are several studies which investigate the needs of caregivers and people with LOD, these results may not be appropriate for understanding the specific necessities of the population with EOD. For instance, Nogueira et al. ${ }^{18}$ suggested that the quality of intimacy in LOD couples may decline as communication difficulties increase and pleasure in each other's company decreases. Declining intimacy and emotional closeness result in a more negative perception of the quality of the marital relationship for spouse-caregivers and a lower quality of the care provided. ${ }^{18}$ Our findings show that most of the EOD caregivers are spouses who face a difficult caregiving context on a daily basis. ${ }^{8}$ However, to the best of our knowledge there is a lack of studies investigating the impact of EOD on these couple's intimacy and sexuality.

Another issue is the limited attention that has been devoted to the costs of care for people with EOD.
Younger people with EOD and their families endure a double economic strain because they often lose their incomes while at the same time they may not be eligible for financial assistance. Additionally, the financial aspects can be exacerbated by the difficulties people with EOD and their families can encounter in arriving at the diagnosis, since they are intensified by the time that elapses between the appearance of the first signs of dementia and diagnosis, which typically exceeds the equivalent period in LOD. ${ }^{13}$

Ducharme et al. ${ }^{19}$ found that not only the PWD themselves should be considered as clients of the health system, but that their caregivers must also be included in this category, since they also have needs and the caregiver role impacts on their health. The lack of special services for younger PWD may also be attributed to the fact that professional staff in general psychiatric services frequently have insufficient knowledge to recognize and treat these disorders. ${ }^{19}$ Better training of health professionals should be aimed at development of specific intervention strategies for EOD, which may be different from those used with people with LOD and their families. Green \& Kleissen ${ }^{20}$ point out that people with EOD and their caregivers have commonly expressed a desire to be put in touch with other people with EOD, rather than being included in services that are aimed at helping older people. The assistance offered to caregivers of people with EOD should take into account the singular features of their situation. The importance of psychoeducational needs is related to the comprehensiveness and complexity of the caregiver role. This role goes beyond the instrumentalization associated with daily caregiving tasks. Nevertheless, there are other aspects of caregiving that are less visible, such as the awareness of disease and the emotional difficulties caused by the daily routine. ${ }^{13,17}$

Some limitations of our study should be acknowledged. First, we had a small sample of caregivers, with homogeneous sociodemographic characteristics, including a majority of women (spouses or daughters) and a homogeneous PWD age range. It can be assumed that the lack of variation in the PWD's ages prevented the assessment from revealing a broader picture of the psychosocial impact of EOD on caregivers. Further studies should control age at EOD onset to categorize the PWD into different subsets. Additionally, we did not assess caregivers' clinical characteristics such as the presence of burden or symptoms of depression and anxiety. However, our study is the first to propose an analysis of the psychosocial impact of an EOD diagnosis on patients' caregivers. The situation of Brazilian caregivers is still under-researched, especially in relation to the caregivers of people with EOD. 
The onset of dementia is always accompanied by serious psychological and emotional difficulties for the people affected by the disease and for their families. These difficulties are exacerbated in the cases of people younger than 65 years old. Frequently, the onset of the disease and its progression is accompanied by a reversal in roles, with children becoming the caregivers of their own parents, even at a relatively young age. ${ }^{13}$ Additionally, when EOD results in loss of employment, the consequences often extend beyond the loss of family income and may have a devastating impact on a person's self-esteem and sense of efficacy and self-worth. ${ }^{8}$ Although the number of support groups for caregivers and individuals with dementia is growing progressively, these services are still relatively scarce and they are designed for people with LOD. One clinical implication of our results is the urgent need for development of psychosocial interventions designed for the carers of people who are diagnosed with dementia under 65 years old, in order to provide better information about the condition, its prognosis, and methods for coping with it.

\section{Acknowledgements}

This study was supported by Fundação de Amparo à Pesquisa do Estado do Rio de Janeiro (FAPERJ; grant no. E-26/102.256/2010).

\section{References}

1. American Psychiatric Association. Diagnostic and Statistical Manual of Mental Disorders, Fourth Edition, Text Revision (DSMIV-TR). Arlington: American Psychiatric Publishing; 2002.

2. van Vliet $D$, de Vugt ME, Bakker C, Koopmans RT, Verhey FR. Impact of early onset dementia on caregivers: a review. Int J Geriatr Psychiatry. 2010;25:1091-100.

3. Vieira RT, Caixeta L, Machado S, Silva AC, Nardi AE, Arias-Carrión $O$, et al. Epidemiology of early-onset dementia: a review of the literature. Clin Pract Epidemiol Ment Health. 2013;9:88-95.

4. Masellis M, Sherborn $K$, Neto $P$, Sadovnick DA, Hsiung GY, Black $\mathrm{SE}$, et al. Early-onset dementias: diagnostic and etiological considerations. Alzheimers Res Ther. 2013;5:S7.
5. Harris PB. The perspective of younger people with dementia: still an overlooked population. Soc Work Ment Health. 2004;2:17-36.

6. Wawrziczny $E$, Antoine $P$, Ducharme F, Kergoat MJ, Pasquier F. Couples' experiences with early-onset dementia: an interpretative phenomenological analysis of dyadic dynamics. Dementia (London). 2014 Oct 9. pii: 1471301214554720. [Epub ahead of print]

7. Arai A, Matsumoto T, Ikeda M, Arai Y. Do family caregivers perceive more difficulty when they look after patients with early onset dementia compared to those with late onset dementia? Int J Geriatr Psychiatry. 2007;22:1255-61.

8. Ducharme F, Lachance L, Kergoat MJ, Coulombe R, Antoine $P$ Pasquier F. A comparative descriptive study of characteristics of early-and late-onset dementia family caregivers. Am J Alzheimers Dis Other Demen. 2015 Mar 26. pii: 1533317515578255. [Epub ahead of print]

9. Smith J, Jarman M, Osborn M. Doing interpretative phenomenological analysis. In: Murray $M$, Chamberlain $K$, editors. Qualitative health psychology: theories and methods. London: Sage Publications; 1999. p. 218-40.

10. Maia AL, Godinho C, Ferreira ED, Almeida V, Schuh A, Kaye J, et al. [Application of the Brazilian version of the CDR scale in samples of dementia patients]. Arq Neuropsiquiatr. 2006;64:485-9.

11. Hawkin SA. The social experiences of spouses of persons with young-onset dementia [dissertation], Hamilton: McMaster University; 2012.

12. Grandi I. Conversando com o cuidador: a doença de Alzheimer. Belém: Grafisa; 1998.

13. Werner P, Stein-Shvachman I, Korczyn AD. Early onset dementia: clinical and social aspects. Int Psychogeriatr. 2009;21:631-6.

14. Rosness TA, Mjørud M, Engedal K. Quality of life and depression in carers of patients with early onset dementia. Aging Ment Health. 2011;15:299-306.

15. Santos RL, de Sousa MF, Ganem AC, Silva TV, Dourado MC. Cultural aspects in dementia: differences in the awareness of Brazilian caregivers. Trends Psychiatry Psychother. 2013;35:191-7.

16. Pereira MFC. Cuidadores informais de doentes de Alzheimer: sobrecarga física, emocional e social e psicopatologia [thesis]. Porto: Universidade do Porto; 2011.

17. Ducharme $F$, Kergoat $M J$, Coulombe R, Lévesque $L$, Antoine $P$, Pasquier F. Unmet support needs of early-onset dementia family caregivers: a mixed-design study. BMC Nurs. 2014;13:49.

18. Nogueira MM, Neto JP, Sousa MF, Santos RL, Rosa RD, BelfortT et al. Spouse-caregivers' quality of life in Alzheimer's disease. Int Psychogeriatr. 2015;27:837-45.

19. Ducharme $F$, Kergoat $M J$, Antoine $P$, Pasquier $F$, Coulombe $R$. Caring for individuals with early-onset dementia and their family caregivers: the perspective of health care professionals. Adv Alzheimer Dis. 2014;3:33-43.

20. Green T, Kleissen T. Early onset dementia: a narrative review of the literature. Ind J Gerontol. 2013;27:1-28.

\section{Correspondence:}

Nathália Kimura

Rua Manoel Pereira, 71

26220-250 - Nova Iguaçu, RJ - Brazil

E-mail: nathaliaramos2@hotmail.com 